\title{
Decentralized Fuzzy Control of Nonlinear Large - Scale Power Systems
}

\author{
Mahmoud Najafi
}

\begin{abstract}
This paper presents a decentralized fuzzy controller for a large-scale nonlinear power system and interconnections represented by nonlinear functions. The effectiveness of the proposed decentralized fuzzy controller is illustrated by considering a two-turbo generator system and related load frequency control. The simulation results verify the merits of the proposed controller.
\end{abstract}

Index Terms-Fuzzy logic control, load frequency control multi-machine power systems.

\section{INTRODUCTION}

In recent years, control design for large scale systems and effort to extend it has attracted much attention. Research in control of large scale systems is motivated by the many emerging applications that employ novel actuation devices for active control of power systems, industrial automation, cooperating robotics systems, and aerospace processes. Centralized control for the large scale systems is usually impractical due to the requirement of a large amount of information exchanges between subsystems and the lack of computing capacity. Knowing that in large-scale systems, practically nonlinear functions, as well as nonlinear interconnections between subsystems are unknown, their approximation is needed. Neural networks and fuzzy models have been considered as a general tool for modeling nonlinear functions [1]. [2-5] introduced the feedback linearization control for large scale power systems and [6-7] presented frequency-domain technique for multivariable large scale systems. [8-9] introduced robust adaptive and sliding mode control for large scale power systems, respectively. Hence, in some of the above-mentioned papers, for simplification the model of turbine and generator has been considered by first order function block. This work proposes a decentralized fuzzy control scheme for a twoturbo generator nonlinear systems and assuming the interconnections are of high order, unknown and nonlinear. The paper is organized as follows. Formulation and modeling of large scale power system are introduced in section II. In section III the decentralized fuzzy controller scheme is presented for large scale power system with considering the nonlinear interactions between the subsystems and in section IV the simulation results are demonstrated the effectiveness of decentralized fuzzy technique. Finally, section V concludes the paper.

Manuscript received June 7, 2012; revised July 30, 2012.

Naushin Nower is with the Institute of Information Technology, University of Dhaka, Dhaka, Bangladesh (e-mail: naushin@iit.du.ac.bd).

Ahsan Raja Chowdhury is with the department of computer science and engineering, University of Dhaka, Dhaka, Bangladesh (e-mail: farhan717@cse.univdhaka.edu).
Manuscript received October 2, 2011.Mahmoud Najafi was at the Control and Instrument Department of National Iranian Oil Company (IOOC) for about 10 years and now is the ICT manager at IOOC (e-mail: mnajafi@iooc.co.ir )

\section{LARGE - SCALE POWER SYSTEM MODELLING}

Large-scale power system can be represented using differential algebraic equations (DAE). The differential algebraic equations represent the generator dynamic and power flow constraints are given respectively by

$$
\left\{\begin{array}{l}
\frac{d \delta_{i}}{d t}=\omega_{i}-\omega_{s} \\
\frac{2 H_{i}}{\omega_{s}} \frac{d \omega_{i}}{d t}=T_{m i}-T_{e i}-K_{d i} \Delta \omega_{i} \\
T_{d o i}^{\prime} \frac{d E_{q i}^{\prime}}{d t}=-E_{q i}^{\prime}-\left(X_{d i}-X_{d i}^{\prime}\right) I_{d i}+E_{f d i}
\end{array}\right.
$$

and

$$
\left\{\begin{array}{l}
P_{i}^{i n j}-V_{i} \sum_{j=1}^{N} V_{j} Y_{j} \cos \left(\theta_{i}-\theta_{j}-\varphi_{j}\right)=0 \\
Q_{i}^{i n j}-V_{i} \sum_{j=1}^{N} V_{j} Y_{j} \sin \left(\theta_{i}-\theta_{j}-\varphi_{j}\right)=0
\end{array}\right.
$$

where $\mathrm{I}_{\mathrm{di}}$ and $\mathrm{I}_{\mathrm{qi}}$ satisfy the following equation:

$$
\left\{\begin{array}{l}
\mathrm{V}_{\mathrm{i}} \sin \left(\delta_{\mathrm{i}}-\theta_{\mathrm{i}}\right)-\mathrm{X}_{\mathrm{qi}} \mathrm{I}_{\mathrm{qi}}=0 \\
\mathrm{~V}_{\mathrm{i}} \cos \left(\delta_{\mathrm{i}}-\theta_{\mathrm{i}}\right)+\mathrm{X}_{\mathrm{di}}^{\prime} \mathrm{I}_{\mathrm{di}}-\mathrm{E}_{\mathrm{qi}}^{\prime}=0
\end{array}\right.
$$

where $i$ is the number of generators, $N$ is the number of the buses, $\mathrm{x}_{\mathrm{di}}^{\prime}$ is the transient reactance and $\delta_{\mathrm{i}}$ is the power angle of the ith generator in $\mathrm{rad}, \omega_{\mathrm{i}}$ is the rotating speed of the ith generator in $\mathrm{rad} / \mathrm{s}, \mathrm{H}_{\mathrm{i}}$ is the inertia constant, $\mathrm{T}_{\mathrm{mi}}$ is the mechanical input power in p.u., $\mathrm{E}_{\mathrm{qi}}^{\prime}$ is the q-axis internal transient electric potential of the ith generator in p.u., $\mathrm{E}_{\mathrm{fdi}}$ is the control signal in p.u., $P_{i}^{i n j}$ and $Q_{i}^{i n j}$ are the injected active and reactive power at bus i in p.u., $V_{i} \angle \theta_{i}$ is the ith bus voltage, $\mathrm{Y}_{\mathrm{j}} \angle \varphi_{\mathrm{j}}$ is admittance between bus $\mathrm{i}$ and $\mathrm{j}$. The difficulty encountered during the controller design for the above DAE based model is the manipulation of algebraic constraints. According to (3), we can see in (1), $\mathrm{I}_{\mathrm{di}}$ and $\mathrm{I}_{\mathrm{qi}}$ are functions of local measured variables $\delta_{i}$ and $\mathrm{V}_{\mathrm{i}} \angle \theta_{\mathrm{i}}$. 
Since $\mathrm{V}_{\mathrm{i}} \angle \theta_{\mathrm{i}}$ is subjected to algebraic equation constraint (2), $\mathrm{I}_{\mathrm{di}}$ and $\mathrm{I}_{\mathrm{qi}}$ can be only expressed as a function of the states of the differential equations. According to circuit theory the voltages and injected currents at the generator buses satisfy the following equation:

$$
\overline{\mathrm{V}}=\mathrm{Z}_{\text {bus }} \overline{\mathrm{I}}
$$

where $\quad \bar{V}=\left[V_{1}, \ldots V_{n}\right]^{T}$ and $\bar{I}=\left[I_{1}, \ldots I_{n}\right]^{T} \in \mathbb{R}^{n \times 1}$ and $Z_{\text {bus }}=R+j X \in \mathbb{R}^{n \times n}$ is a matrix of the equivalent impedance of the network. The dynamic circuit of the synchronous generator can be represented using the Fig. 1.

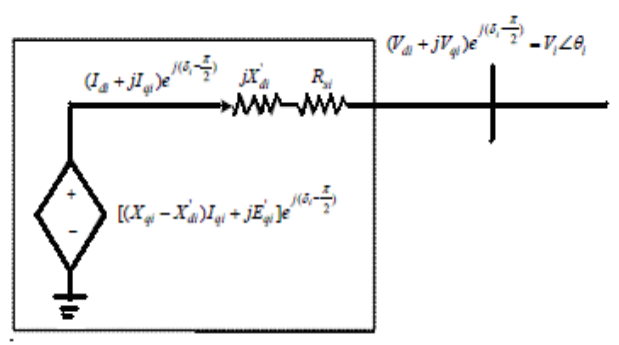

Fig. 1. .Dynamic circuit of synchronous generator

According to the figure 1, we have

$$
\overline{\mathbf{I}}=\left(\mathbf{I}_{\mathbf{d}}+\mathbf{j} \mathbf{I}_{\mathbf{q}}\right) e^{\mathrm{j}\left(\delta-\frac{\pi}{2}\right)}
$$

And

$$
\left.\overline{\mathrm{V}}=\left[\left(\mathrm{X}_{\mathrm{q}} \cdot \mathrm{I}_{\mathrm{q}}-\mathrm{R}_{\mathrm{S}} \cdot \mathrm{I}_{\mathrm{d}}\right)+\mathrm{j}\left(\mathrm{E}_{\mathrm{q}}^{\prime}-\mathrm{X}_{\mathrm{d}}^{\prime} \cdot \mathrm{I}_{\mathrm{d}}-\mathrm{R}_{\mathrm{S}} \cdot \mathrm{I}_{\mathrm{q}}\right)\right]\right]^{\mathrm{j}\left(\delta-\frac{\pi}{2}\right)}
$$

where

$$
\begin{gathered}
\mathrm{I}_{\mathrm{d}}=\left[\mathrm{I}_{\mathrm{d} 1}, \ldots \mathrm{I}_{\mathrm{dn}}\right]^{\mathrm{T}}, \mathrm{I}_{\mathrm{q}}=\left[\mathrm{I}_{\mathrm{q} 1}, \ldots \mathrm{I}_{\mathrm{qn}}\right]^{\mathrm{T}}, \delta=\left[\delta_{1}, \ldots \delta_{\mathrm{n}}\right]^{\mathrm{T}}, \\
\mathrm{X}_{\mathrm{q}}=\left[\mathrm{X}_{\mathrm{q} 1}, \ldots \mathrm{X}_{\mathrm{qn}}\right]^{\mathrm{T}}, \mathrm{X}_{\mathrm{d}}^{\prime}=\left[\mathrm{X}_{\mathrm{d} 1}^{\prime}, \ldots \mathrm{X}_{\mathrm{dn}}^{\prime}\right]^{\mathrm{T}}, \mathrm{E}_{\mathrm{q}}^{\prime}=\left[\mathrm{E}_{\mathrm{q} 1}^{\prime}, \ldots \mathrm{E}_{\mathrm{qn}}^{\prime}\right]^{\mathrm{T}}, \\
\mathrm{R}_{\mathrm{S}}=\left[\mathrm{R}_{\mathrm{s} 1}, \mathrm{R}_{\mathrm{sn}}\right]^{\mathrm{T}}, \mathrm{X}_{\mathrm{d}}^{\prime}=\left[\mathrm{X}_{\mathrm{d} 1}^{\prime}, \ldots \mathrm{X}_{\mathrm{dn}}^{\prime}\right]^{\mathrm{T}}, \mathrm{E}_{\mathrm{q}}^{\prime}=\left[\mathrm{E}_{\mathrm{q} 1}^{\prime}, \ldots \mathrm{E}_{\mathrm{qn}}^{\prime}\right]^{\mathrm{T}}, \\
\text { And } \mathbf{R}_{\mathrm{S}}=\left[\mathbf{R}_{\mathrm{s} 1}, \ldots \mathrm{s}_{\mathbf{s}}\right]^{\mathrm{T}} .
\end{gathered}
$$

Since elements of $R_{S}$ are usually very small, we assume the $R_{S}$ as a null vector. Substituting (5) and (6) into (3) produces:

$$
\left[\mathrm{X}_{\mathrm{q}} \cdot \mathrm{I}_{\mathrm{q}}+\mathrm{j}\left(\mathrm{E}_{\mathrm{q}}^{\prime}-\mathrm{X}_{\mathrm{d}}^{\prime} \cdot \mathrm{I}_{\mathrm{d}}\right)\right] \mathrm{e}^{\mathrm{j}\left(\delta-\frac{\pi}{2}\right)}=(\mathrm{R}+\mathrm{jX})\left[\left(\mathrm{I}_{\mathrm{d}}+\mathrm{jI}_{\mathrm{q}}\right) \mathrm{e}^{\mathrm{j}\left(\delta-\frac{\pi}{2}\right)}\right]
$$

That is equal as

$\left\{\begin{array}{l}\mathrm{X}_{\mathrm{q}} \cdot \mathrm{I}_{\mathrm{q}} \sin \delta+\left(\mathrm{E}_{\mathrm{q}}^{\prime}-\mathrm{X}_{\mathrm{d}}^{\prime} \cdot \mathrm{I}_{\mathrm{d}}\right) \cos \delta=\mathrm{R}\left(\mathrm{I}_{\mathrm{d}} \cdot \sin \delta+\mathrm{I}_{\mathrm{q}} \cdot \cos \delta\right)-\mathrm{X}\left(\mathrm{I}_{\mathrm{q}} \cdot \sin \delta-\mathrm{I}_{\mathrm{d}} \cdot \cos \delta\right) \\ \left(\mathrm{E}_{\mathrm{q}}^{\prime}-\mathrm{X}_{\mathrm{d}}^{\prime} \cdot \mathrm{I}_{\mathrm{d}}\right) \sin \delta-\mathrm{X}_{\mathrm{d}} \cdot \mathrm{I}_{\mathrm{a}} \cdot \cos \delta=\mathrm{R}\left(\mathrm{I}_{\mathrm{q}} \sin \delta-\mathrm{I}_{\mathrm{d}} \cdot \cos \delta\right)+\mathrm{X}\left(\mathrm{I}_{\mathrm{d}} \cdot \sin \delta+\mathrm{I}_{\mathrm{q}} \cdot \cos \delta\right)\end{array}\right.$

Considering the ith elements of the above equations, we obtain

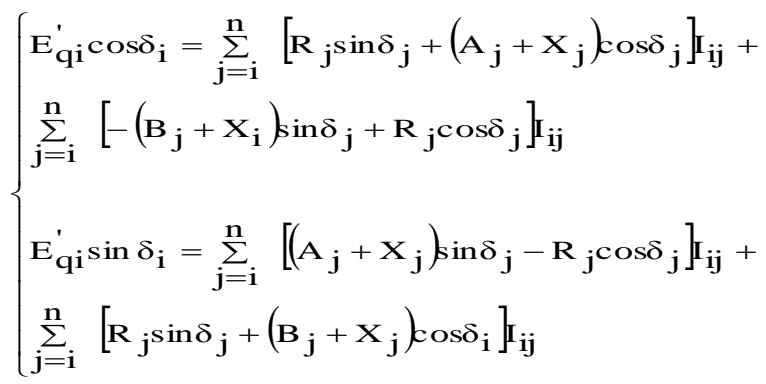

where $\mathrm{R}_{\mathrm{ij}}$ and $\mathrm{X}_{\mathrm{ij}}$ are the ith and $j$ th element of $R$ and $X$ respectively. In above equation, $A$ and $B$ are defined according to $\mathbf{A}=\operatorname{diag}\left[\mathbf{x}_{\mathbf{d} 1}^{\prime}, \ldots \mathbf{x}_{\mathbf{d n}}^{\prime}\right\rfloor \quad$ and $\mathrm{B}=\operatorname{diag}\left[\mathrm{X}_{\mathrm{q} 1}, \ldots, \mathrm{X}_{\mathrm{qn}}\right]$. Now, consider the excitation and speed governor system equations in ith machine as described by:

$$
\begin{aligned}
& \dot{\mathrm{E}}_{\mathrm{fd}_{\mathrm{i}}}=-\frac{\Delta \mathrm{E}_{\mathrm{fd}_{\mathrm{i}}}}{\mathrm{T}_{\mathrm{A}_{\mathrm{i}}}}+\frac{\mathrm{K}_{\mathrm{A}_{\mathrm{i}}}}{\mathrm{T}_{\mathrm{A}_{\mathrm{i}}}} \Delta \mathrm{V}_{\mathrm{i}_{\mathrm{i}}}+\frac{\mathrm{K}_{\mathrm{A}_{\mathrm{i}}}}{\mathrm{T}_{\mathrm{A}_{\mathrm{i}}}} \mathrm{U}_{\mathrm{f}_{\mathrm{i}}} \\
& \dot{\mathrm{P}}_{\mathrm{m}_{\mathrm{i}}}=-\frac{\mathrm{P}_{\mathrm{m}_{\mathrm{i}}}}{\mathrm{T}_{\mathrm{Gi}_{\mathrm{i}}}}+\frac{\mathrm{K}_{\mathrm{g}_{\mathrm{i}}}}{\mathrm{T}_{\mathrm{G}_{\mathrm{i}}}} \frac{\Delta \omega_{\mathrm{i}}}{\mathrm{W}_{0}}+\frac{\mathrm{P}_{\mathrm{mo}_{\mathrm{i}}}}{\mathrm{T}_{\mathrm{G}_{\mathrm{i}}}}+\frac{\mathrm{K}_{\mathrm{Gi}_{\mathrm{i}}}}{\mathrm{T}_{\mathrm{Gi}_{\mathrm{i}}}} \mathrm{U}_{\mathrm{G}_{i}}
\end{aligned}
$$

where Uf and UG are excitation system and speed governor control signal, respectively. Here, consider the connection of two interconnected machines in Fig. 2.

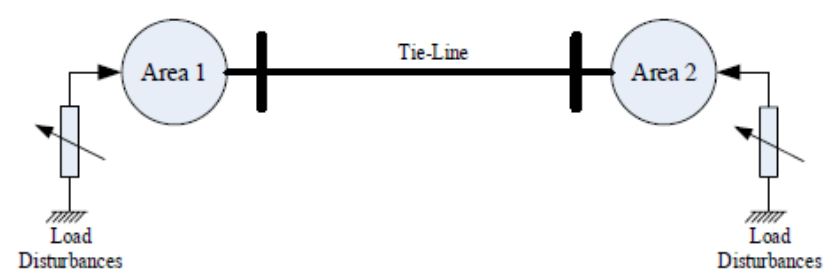

Fig. 2. Two area interconnected system

The state equation of each machine can be expressed by

$$
\begin{aligned}
& \dot{\mathrm{X}}=\mathrm{F}(\mathrm{X})+\mathrm{G} \cdot \mathrm{U} \\
& \mathrm{Y}=\mathrm{H}(\mathrm{X})
\end{aligned}
$$

where

$$
\begin{aligned}
& \mathrm{X}=\left\lfloor\Delta \delta, \Delta \omega, \mathrm{E}_{\mathrm{q}}^{\prime}, \mathrm{E}_{\mathrm{fd}}, \mathrm{P}_{\mathrm{m}}\right\rfloor \\
& \mathrm{U}=\left[\mathrm{U}_{\mathrm{f}}, \mathrm{U}_{\mathrm{G}}\right] \\
& \mathrm{Y}=\left[\Delta \delta, \Delta \mathrm{V}_{\mathrm{t}}\right]=\left[\mathrm{h}_{1}(\mathrm{X}), \mathrm{h}_{2}(\mathrm{X})\right] \\
& \mathrm{G}=\left[\mathrm{g}_{1}, \mathrm{~g}_{2}\right] \\
& \mathrm{g}_{1}=\left[\begin{array}{lllll}
0 & 0 & 0 & \frac{\mathrm{K}_{\mathrm{A}}}{\mathrm{T}_{\mathrm{A}}} & 0
\end{array}\right]^{\mathrm{T}} \\
& \mathrm{g}_{2}=\left[\begin{array}{lllll}
0 & 0 & 0 & 0 & \frac{\mathrm{K}_{\mathrm{G}}}{\mathrm{T}_{\mathrm{G}}}
\end{array}\right]^{\mathrm{T}}
\end{aligned}
$$

By the above assumptions for each machine the nonlinear fuzzy controller discussed below is designed to control and stabilize the system in face of a load disturbance occurred in system. 


\section{NONLINEAR FUZZY LOGIC CONTROLLER}

This section presents a fuzzy controller for (12) with nonlinear interconnection functions. The method of fuzzification has found increasing applications in power systems. The applications of fuzzy sets signify a major enhancement of power systems analysis by avoiding heuristic assumptions in practical cases. This is because fuzzy sets could be deployed properly to represent power system uncertainties. The operation principle of a fuzzy logic controller is similar to a human operator. It performs the same actions as a human operator does by adjusting the input signal looking at only the system output. A fuzzy logic based controller consists of three sections namely fuzzifier, rule base, and defuzzifier. The inputs are first fuzzified and converted to fuzzy membership values that are used in the rule base in order to execute the related rules so that an output can be generated. Membership Function (MF) specifies the degree to which a given input belongs to a set. The membership functions of the fuzzy logic controller presented in Fig. 3 consist of three memberships functions (inputs1 and input2 and one-output). Each membership function has seven memberships, comprising two trapezoidal and five triangular memberships. All memberships are selected to describe all linguistic variables. Fuzzy rules are conditional statement that specifies the relationship among fuzzy variables. These rules help us to describe the control action in quantitative terms and have been obtained by examining the output response to corresponding inputs to the fuzzy controller. In order to model the actions that a human operator would decide whether the $u$, in the controller output is to be increased or decreased according to the error $(e)$ and its deviation $(\Delta e)$, it is necessary to observe the behaviors of the signal $e$ and its $\Delta e$ on different operating regions in Fig. 3. The output $\mathrm{u}$ from the fuzzy logic controller is the change that is required to increase or decrease the overall control action to the controlled system. Therefore, the signs of $e$ and $\Delta \mathrm{e}$ are used to determine the signs of $u$, which determines whether the overall control signal is to be increased.

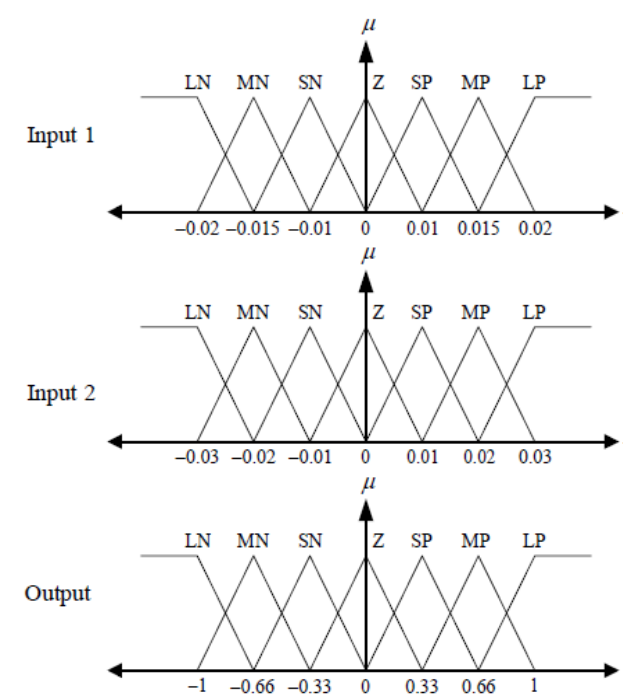

$\mathrm{LN}$ : large negative, $\mathrm{MN}$ : medium negative, $\mathrm{SN}$ : small negative , $\mathrm{Z}$ : zero SP: small positive , MP: medium positive, LP: large positive

Fig. 3. Operating regions and membership function for nonlinear fuzzy logic controller

\section{IMPLEMENTATION AND RESULTS}

In this section, we apply the proposed decentralized fuzzy controller to control two areas of power system which is connected through a tie line. The numerical values of the physical parameters of each area are shown in Table 1. To show the effectiveness of the proposed method, two different controllers are studied in order to compare the results. We will first demonstrate how a simple decentralized proportional plus integral (PI) controller, would control the system. Frequency deviations after a step load disturbance are considered. Frequency deviations in area 1 and 2 with PI controller are shown in figures 4 and 5 . We find the PI controller does not provide good control performance. The decentralized fuzzy controller proposed in Section 4 is then applied to the system. Figures 4 and 5 show the simulation results for the designed controller. Finally, the frequency control effects of conventional PI and fuzzy logic controllers are evaluated under different random step load variations that are applied to first area as indicated in Fig 6 . The result of the frequency deviations of the first area is shown in Fig.7.

And in Fig.8 the result of $T_{m}-T_{e}$ is shown under the different random step load change which previously discussed. Comparing the results in Fig. 4, 5, 7 and 8, it can be observed that the proposed decentralized fuzzy controller presents a more desirable performance.

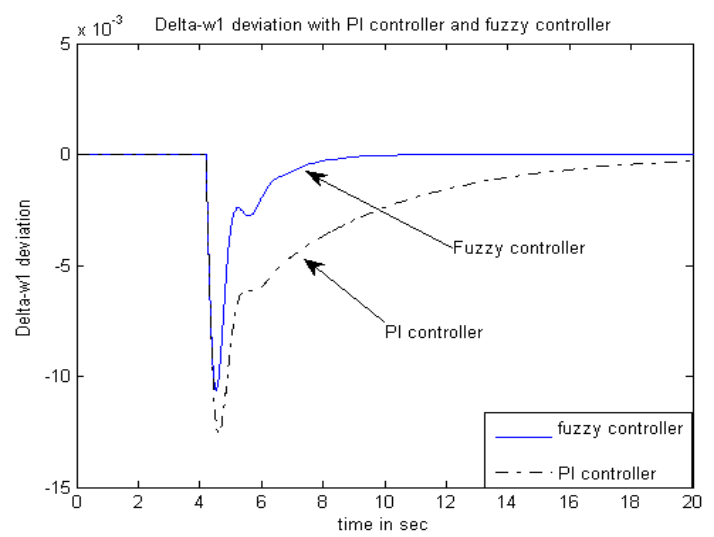

Fig. 4. Frequency deviations in area 1 after a step load disturbance with the conventional PI and fuzzy logic controller.

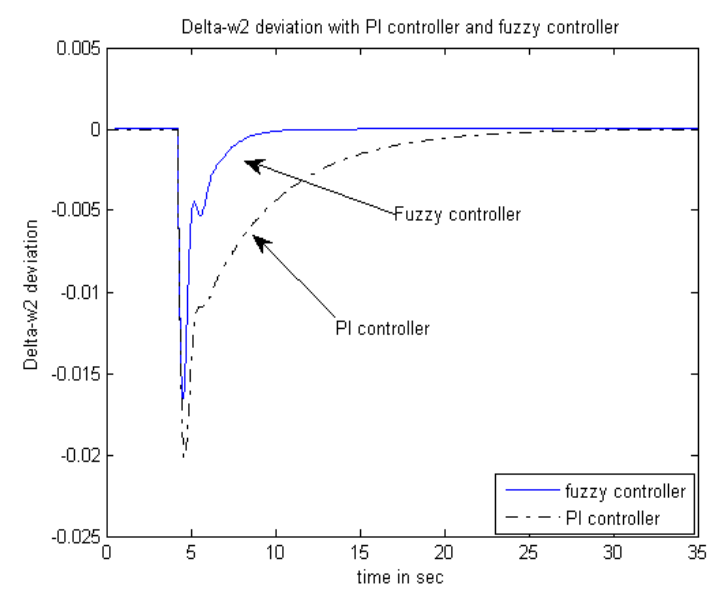

Fig. 5. Frequency deviations in area 2 after a step load disturbance with PI and fuzzy logic controller. 


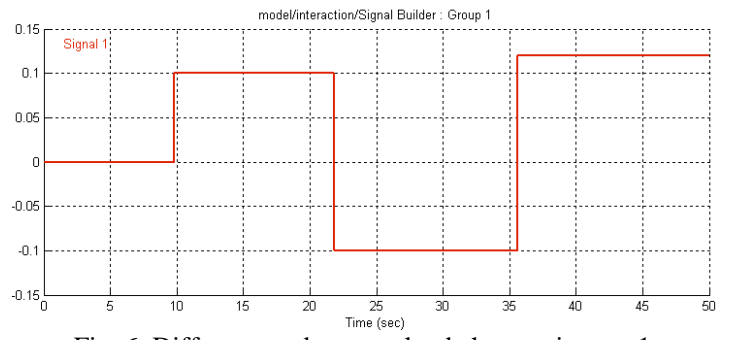

Fig. 6. Different random step load changes in area 1

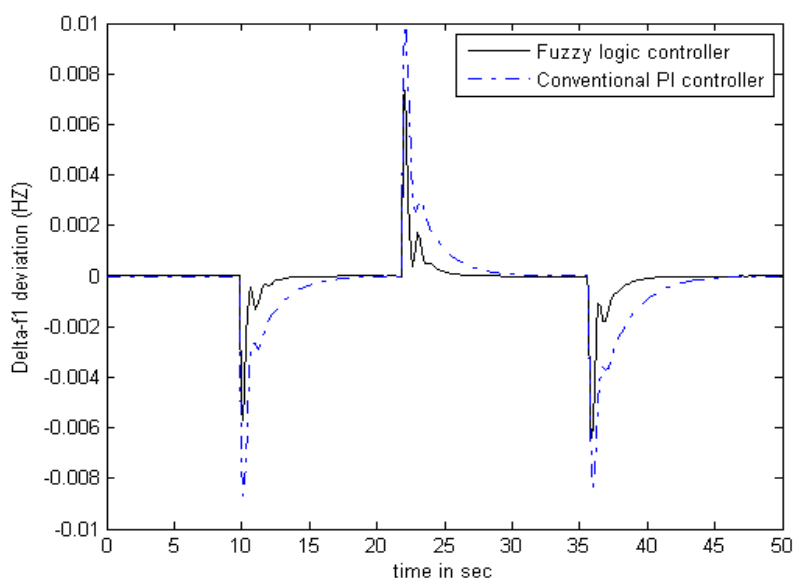

Fig. 7. Time response of frequency deviation under load change

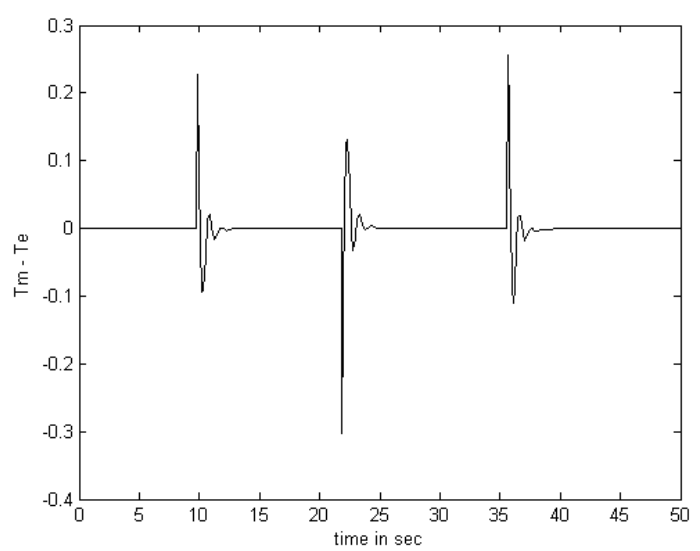

Fig. 8. Time response of Tm - Te under random step load change

\section{CONCLUSION}

In this paper fuzzy logic controller is proposed for load frequency control scheme of a two area interconnected power systems with nonlinearities and interactions between areas. Both conventional PI controller and fuzzy logic controller are used to compare the results in which it was shown that due to the fix value of PI gains, PI controller did not provide good control performance and the fuzzy logic controller presented a more desirable performance.
TABLE I: GENERATOR CONSTANTS

\begin{tabular}{|c||c|c||}
\hline & Generator G1 & Generator G2 \\
\hline \hline xd [p.u.] & 1.569 & 1.651 \\
\hline xd' [p.u.] & 0.324 & 0.232 \\
\hline xd' [p.u.] & 0.249 & 0.171 \\
\hline xq [p.u.] & 1.548 & 1.590 \\
\hline xq' [p.u.] & 0.918 & 0.380 \\
\hline xq" [p.u.] & 0.248 & 0.171 \\
\hline xl [p.u.] & 0.204 & 0.102 \\
\hline Td0' [s] & 5.140 & 5.900 \\
\hline Td0" [s] & 0.0437 & 0.033 \\
\hline Tq0' [s] & 0.500 & 0.535 \\
\hline Tq0” [s] & 0.070 & 0.078 \\
\hline D [p.u.] & 2.000 & 2.000 \\
\hline$\omega 0=2 \pi$ f[rad/s] & $120 \pi$ & $120 \pi$ \\
\hline H [MW-Sec/MVA] & 50.00 & 9.00 \\
\hline Capacity[GVA] & 6000 & 2 \\
\hline
\end{tabular}

\section{REFERENCES}

[1] B. Karimi, M. B. Menhaj, M. K. Ghartemani, and I. Saboori, "Decentralized adaptive control of large-scale affine and non-affine nonlinear systems," IEEE Trans. Instrum. Meas, vol. 58, no. 8, 2009. pp. 2459-2467

[2] P. W. Sauer and M. A. Pai, "Power system dynamics and stability," Prentice Hall, 1997.

[3] J. W. Chapman, M. D. Ilic, C. A. King, L. Eng, and H. Kaufman, "Stabilizing a Multi-machine Power System via Decentralizing Feedback Linearizing Excitation Control," IEEE Transactions on Power Systems, vol. 8, no. 3, August, 1993, pp. 830-839.

[4] Q. Lu and Y. Z. Sun, "Nonlinear Stabilizing Control of Multimachine Systems," IEEE Transactions on Power Systems, vol. 4, no. 1, February, 1989, pp. 236-241.

[5] Q. Lu, Y. Sun, Z. Xu, and T. Mochizuki, "Decentralized Nonlinear Optimal Excitation Cont,rol," IEEE Transactions on Power Systems, vol. 11, no. 4, November, 1996, pp1957-1962.

[6] J. Wu, A. Yokoyama, Q. Lu, M. Goto, and H. Konishi, "MIMO Decentralized Nonlinear Control of Generator and Turbine To Enhance Transient Stability of Power System," Annual Conference of Power and Energy Society, IEE of Japan,

[7] F. Crusca, "Multivariable Frequency-Domain Techniques for the Systematic Design of Stabilizers for Large-Scale Power Systems" Transactions on Power Systems, vol. 6, no. 3, August 1991.

[8] A. F. Okou, L. A. Dessaint, "Globally Stabilizing Robust Adaptive Voltage and Speed Regulator for Large-Scale Power Systems," 44th IEEE Conference on Decision and Control, and the European Control Conference, 2005.

[9] A. G. Loukimov, "Sliding Mode Control of Large Scale Power Systems," 2004 5th Asian Control Conference.

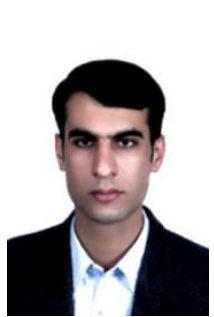

Mahmoud Najafi Applied Electronic Engineer by National university of Iran (2003) And Master of science In Electrical Control Engineering by National Azad University Of Iran (2010) .Has worked about 10 years at the Industrial Control and Instrument Department Of Iranian Offshore oil Company (IOOC). Now is the ICT manager of (IOOC). 